\title{
correspondence
}

\section{High energy consumption or low economic growth?}

SIR,---In arriving at his solution (27 April, page 744) Mr Frank Hooley, MP rejects the underlying assumption in the UK policy (and indeed in the national policy of most other countries) that there is a close relationship between the availability of energy and economic well-being. He bases his rejection on some observations about the trend in 'heat supplied' to households and to some sections of industry.

$\mathrm{Mr}$ Hooley is unfair to charge "nuclear power interests" with attempting to mislead the public by references to energy gaps. Atomic energy spokesmen were among the first to point out that a gap could not exist in practice (see 'Energy Prices and the Role of Nuclear Power' A tom August 1977). But the reason is very different from that given by $\mathrm{Mr}$ Hooley. It is that prices rise to bring supply and demand into balance so that industrial and domestic consumers suffer by being unable to afford the energy they need. This certainly leaves them with a gap between what they would like and what they can afford.

No one pretends that the relationship between energy consumption and economic output is simple - it is, for example, complicated by changes in the efficiency of energy use and by the substitution of one type of fuel for another, since the various fuels are not equally efficient, therm for therm, in promoting economic output. In studies of energy requirements, quality of energy is just as important as quantity. Mr Hooley overlooks this very important factor in his own cursory analysis of the trend in domestic energy use. Households have been able to maintain or even slightly reduce the 'heat' they consume (it is not all used as heat) because they have iwitched to energy forms of much higher quality - from coal to gas, electricity and to a lesser extent, oil. This substitution has been accompanied by a substantial increase in the primary chergy consumed to meet this 'heat' requirement-because initially coal was converted to gas and electricity with some crude energy losses that reflected the greater thermodynamic efficiency of the energy finally delivered to the user. This process has been brought to a halt by the substitution of natural gas for town gas, but natural gas will not be available forever and we could see some resumption of the trend when domestic users switch back to electricity or manufactured gas.

The same trend can be discerned in some industrial uses of fuel. Mr Hooley is right to observe that the steel industry has been reducing its heat requirements per ton of steel. but it electricity requirements per ton of stee have been steadily increasing; and the general trend in industry is towards a product mix with a higher electricity content -which is tending to offset some of the energy savings due to improvements in plant efficiency. It is however very important that these savings should continue to be made, and the Department of Energy figures incorporate a saving of $24^{\circ}$, by the end of the century by conservation measures of one sort or another. Many experts regard this as optimistic.

Many anecdotal examples can be produced to show that we ought to be able to maintain and improve our economic wellbeing whilst holding energy consumption constant or even reducing it; and we can point to massive improvements in the efficiency of energy use that have taken place over the last century. But all the evidence is that countries are unable to sustain a pattern of falling energy consumption alongside rising output. For the world as a whole, the energy growth rate has been somewhat higher than the economic growth rate, despite all the improvements that have taken place in the efficiency of energy use, and some theoretical arguments can be advanced that at least go some way to explain this.

It would be irresponsible, on the basis of an analysis as simple as Mr Hooley's, to assume that our finite North Sea energy reserves will be sufficient to look after us until very speculative sources of energy are available at the right price and in the right quantities. Price is just as important as quantity. If the problem is seen as that of steeply rising prices then it is no solution to offer other energy sources that might turn out to be just as expensive as those they are intended to substitute.

Nuclear fired electric power is cheaper than the alternatives todaywhich is why electricity utilities throughout the world peefer it and why its further development attracts substantial funds. If and when the alternative energy sources reach similar stages of development and promise they too will attract much higher levels of funding. At the moment they are receiving all the funds they can absorb and are not being crowded out by the funds allocated to nuclear devclopment.

Nuclear capacity projections have, as $\mathrm{Mr}$ Hooley says, been scaled down (although not by as much as the reference to figures quoted under a misunderstanding by the Royal Commission on Environmental Pollution might imply), but this has been because of an unprecedentedly prolonged cconomic recession and strong competition from very cheap natural gas. There is no reason to suppose that the current projections, or even higher ones, cannot be achieved. The power plant industry has, in the past, demonstrated its ability to maintain a building programme at the required rate. The existence of some surplus generating plant is no obstacle; Generating Board spokesmen have pointed out that the surplus is more apparent than real and that base load nuclear plants ordered in the immediate future would be fully used to the economic advantage of the electricity system. Electricity economics depend upon both running costs and capital costs and it is misleading to put the spotlight upon nuclear capital costs when the running costs of the only effective alternatives are so much higher and likely to get higher still. Within the timescale that alternatives to coal, oil and gas are needed, the renewable energy sources are unlikely to constitute more than a small, unreliable and, very possibly, costly source of electricity. Their possibilities should continue to be examined because we cannot afford to overlook any possible future energy source. But we should try to keep what they have to offer in perspective. Recent correspondence in your columns have shown how often the proponents of alternatives to nuclear energy plans seem to get their facts wrong and to overstate their cases.

We can agree with the first of Mr Hooley's three final points. We should certainly not overlook the world market for power equipment of all types. Our off-shore oil and gas technology is already showing promise; and if, as seems likely, fast reactors turn out to be the preferred way of generating base load electricity we shall be glad that we remained in the forefront of the development of this technology.

It is also important not to overlook the needs of the poor countries of the world, and technologies like solar energy may have more to offer them. Their main difficulties, however, are shortages of capital and low incomes making rising energy prices hit them especially hard. If the developed countries continue to exploit low-cost nuclear energy then we are more likely to have the buoyant economies that produce surpluses of resources that can be invested in the poorer countries; and the effect of an expanding new, low-cost source of electricity will tend to keep all energy prices in check to some extent, to the benefit of rich and poor countries alike. We cannot accept, however, that there are any obvious advantages in flexibility, economics and environmental intrusion in going for small local power systems rather than inter-connected ones on the present pattern.

Inter-connection provides economies of scale and the ability to deal with the failure of any single plant by the touch of a switch. The envitonmental advantages of separating power production from habitation seem too obvious to need spelling out.

Yours faithfully,

L. G. BRoOKES 